Article

\title{
Visualizing the Intellectual Structure of Eye Movement Research in Cartography
}

\author{
Shuang Wang ${ }^{1}$, Yufen Chen ${ }^{1, *}$, Yecheng Yuan ${ }^{2}$, Haiyun $\mathrm{Ye}^{3}$ and Shulei Zheng ${ }^{1}$ \\ 1 Zhengzhou Institute of Surveying and Mapping, Zhengzhou 450052, China; wangsh@lreis.ac.cn (S.W.); \\ z_score2@163.com (S.Z.) \\ 2 State Key Laboratory of Resources and Environmental Information System, Institute of Geographic Sciences \\ and Natural Resources Research, Chinese Academy of Sciences, Beijing 100101, China; yuanyc@lreis.ac.cn \\ 3 Department of Geography, University of California, Santa Barbara, CA 93106-4060, USA; \\ hiy5064@gmail.com \\ * Correspondence: cyfbeijing@163.com; Tel.: +86-371-8162-2294
}

Academic Editor: Wolfgang Kainz

Received: 7 July 2016; Accepted: 18 September 2016; Published: 23 September 2016

\begin{abstract}
Eye movement research is a burgeoning frontier area in cartography that has attracted much attention from cartographers. However, the substantial amount of relevant literature poses a challenge for researchers aiming to obtain a rapid understanding of the intellectual structure of this research field. The purpose of this paper is to introduce the use of bibliometric analysis methods and multiple visual metaphors to visualize the intellectual structure of eye movement research in cartography, including the classic literature, research theme clusters, and research hotspots, etc. We also explain the use of geovisualization method, which can efficiently represent the spatial distribution of scientific power. Although the analysis results may not fully describe the whole research field, this method is generally applicable. We hope that it will not only help researchers to quickly grasp the evolution and trends of this research field, but will also become a novel method of merging geovisualization with knowledge visualization.
\end{abstract}

Keywords: eye movement; eye tracking; cartography; geovisualization; knowledge visualization

\section{Introduction}

Eye movement research involves eye movement analysis and eye tracking techniques [1] Eye movement analysis refers to the analysis of gaze data and it is considered an outward manifestation of visual/cognitive processing [2], while eye tracking techniques refer to the methods of gaze capturing. Eye movement research emerged almost a century ago and has contributed much to reading psychology, education psychology, consumer psychology, sports psychology, and traffic psychology [3-7], as well as neuroscience, industrial engineering, human factors, and computer science [8,9]. Since the 1970s, cartography research has used eye movement strategies. For example, users' map-reading behaviors have been explored to improve map design and map legibility [10,11], and differences in users' performance can represent differences in spatial cognition ability [12,13]. Spatial cognition has been attracting cartographers' attention for a long time. Robinson's 1952 publication, The look of maps: An examination of cartographic design, is considered seminal in cognitive map research [14]. The author called for cognitive cartographers to systematically observe, collect, and explore data on how people look at and interpret maps, thus leading to the development of empirical approaches. One of the most important empirical approaches is eye movement research. With the development of eye trackers and eye tracking techniques, eye movement research has been widely used in research on animated maps $[15,16]$, map interaction $[17,18]$, web mapping $[19,20]$, and way-finding with mobile eye-trackers [21,22]. 
The scientific literature of one research field reflects the dynamic development of that field. However, it is difficult for researchers to quickly establish the understanding of the evolution and trends of their research field if the amount of scientific publications is substantial. Scientometrics provides effective bibliometric analysis methods to analyze scientific literature and can help researchers efficiently explore their specialty knowledge domain, which have already been applied in many research fields, for example, regenerative medicine [23], schizophrenia research [24], recommendation system research [25], bioenergy research [26], and geographic information systems (GIS) [27]. However, there has been no relevant research about cartography, especially about some emerging trends like eye movement research in cartography. On the other hand, the visual representations of the results directly produced by bibliometric analysis tools are not intuitively understandable. Therefore, the purpose of this paper is to analyze and visualize the intellectual structure of eye movement research in cartography with bibliometric analysis methods and multiple visual metaphors. The term "intellectual structure" used here includes classic literature, research theme clusters, research hotspots, and collaboration patterns indicating authorities in this research field. In addition to bibliometric analysis methods, we also used the geovisualization method for scientific collaboration analysis, which can efficiently represent the spatial distribution of scientific power. Although the results may not fully describe the whole knowledge domain, it can help researchers who are new to eye movement research in cartography to quickly explore the achievements and new trends in this field.

The structure of this paper is organized as follows: Section 2 describes the current bibliometric analysis methods and tools, Section 3 presents the data and workflow, Section 4 illustrates the analysis results, and Sections 5 and 6 give the discussion and conclusions of our work.

\section{Bibliometric Analysis Methods and Tools}

The current widely used bibliometric analysis methods include co-citation analysis, bibliographic coupling analysis, and co-occurrence analysis (e.g., co-citation analysis to explore the structure and evolution of a research field [28], bibliographic coupling analysis for patent grouping [29], co-occurrence analysis of authors to detect research groups and author productivity [30], and co-occurrence analysis of keywords for research hot spots [31]). Details of these methods are described as below.

\section{Co-Citation Analysis}

Co-citation, introduced by Small and Griffith [32], is defined as the frequency with which two documents are cited together. If two scientific documents are cited by another document, there is a co-citation relationship between the two documents. The more frequently the two documents are cited together, the closer the relationship between them. Co-citation can be used not only for literature analysis (called "document co-citation"), but also for author co-citation or journal co-citation [33].

Chen [34] has conceptualized a specialty as a time-variant duality between two fundamental concepts: research fronts and intellectual bases. Research fronts are defined as emergent and transient groupings of concepts and underlying research issues; the publications cited by research fronts comprise the intellectual bases. Document co-citation analysis has been used to study intellectual bases by many researchers, which allows the identification of key works $[35,36]$. It is worth emphasizing that, because document co-citation is dependent on the citing literature, its patterns can change over time.

\section{Bibliographic Coupling Analysis}

Kessler [37] found that the more similar two papers' research interests are, the more co-citations these papers receive, and the relationship between citing papers was defined as bibliographic coupling relationship. If two papers cite the same paper, these two papers are coupled papers. Coupling strength is the number of shared cited papers; higher coupling strength indicates a greater similarity in research theme. Furthermore, we can cluster the bibliographic coupling network to visualize the theme communities of the network. Generally, bibliographic coupling analysis is used to identify sets of recent 
papers [38]. It differs from co-citation analysis because a paper's citations cannot be modified after it is published; therefore, the bibliographic coupling relationship is fixed and permanent. In addition to bibliographic coupling analysis, author coupling and journal coupling are also effective ways to explore the similarity of author interests or journal themes.

\section{Co-Occurrence Analysis}

Co-occurrence analysis provides a quantitative method to obtain concurrence information from any information carriers [39]. Concurrence is a linguistics term; co-occurrence analysis can either detect concurrence or the above-chance frequent occurrence of two terms from a text corpus. Based on co-occurrence analysis, co-words analysis is a content analysis method that analyzes the co-occurrence of paired items (i.e., keywords or noun phrases) in a text corpus to detect the relationships between ideas within the subject areas presented in these texts [40]. Co-word analysis seeks to extract the themes and explore the linkages among them within the scientific literature; as a result, it can be used to reflect both research topics and evolving frontiers [41].

Co-occurrence analysis can be broadened to co-author analysis, or co-institution analysis and co-country/territory analysis, which can reveal scientific collaboration patterns. Generated co-occurrence networks provide graphic visualization of relationships between terms, authors, institutions, or other objects.

Many tools have been developed to facilitate interpretation of bibliometric analysis results, including CiteSpace, Bibexcel, Science of Science $\left(\mathrm{Sci}^{2}\right)$ Tool, and VOSViewer [42]. Among them, CiteSpace is an out-of-box, user-friendly and powerful software. It is a freeware, Java-based application developed by Chen for mapping scientific knowledge, and it has been continuously updated [34]; the version used in this paper is 4.0. CiteSpace can read various kinds of bibliographic source formats, such as Web of Science (WOS), PubMed, Scopus, ADS, arXiv, NSF, and some Chinese database formats (e.g., Chinese National Knowledge Infrastructure [CNKI] and Chinese Social Sciences Citation Index [CSSCI]). It can generate and visualize networks comprising many nodes and edges, and can prune networks using a minimum spanning tree algorithm or pathfinder algorithm. It provides three views to display the network: cluster view, timeline view, and time zone view. For the cluster view, either the static form or the time slices form can be chosen; the latter splits the network by time interval. The timeline or time zone views show the nodes and edges as a time series form, which can explore the evolution of scientific literature.

Another useful functionality of CiteSpace is using cluster detection algorithm to divide a network into subgroup [34]. After clustering, CiteSpace can label each cluster with terms extracted from document titles, keywords, or abstracts. The terms which are usually noun phrases can be ranked by three algorithms which are $\mathrm{tf}^{*}$ idf (term frequency-inverse document frequency), LLR (log-likelihood ratio) test, and MI (mutual information) provided by CiteSpace [43]. Tf*idf multiples two quantities tf and idf and is a metric to reflect how important a word is to a corpus [44]; the LLR test is a statistical test to compare two models' goodness of fit based on likelihood ratio [45]; MI indicates a reduction in uncertainty measures of how much one random variable tells us about another [46]. Terms selected by tf*idf tend to reflect a cluster's most salient aspect, while the other two algorithms give a unique aspect of a cluster [43].

Although CiteSpace is powerful for bibliometric analysis, the visualization output is not very satisfactory and the software lacks geovisualization functionality. Therefore, we have used other visualization tools in addition to CiteSpace to achieve better representations which will be described in the next section.

\section{Data and Methodology}

\subsection{Data}

The data used in this paper were obtained from WOS, which is considered one of the most comprehensive and high-quality online bibliographic sources. The WOS core collection citation indexes 
include Science Citation Index Expanded (SCI-EXPANDED), Social Sciences Citation Index (SSCI), Arts and Humanities Citation Index (A\&HCI), Conference Proceedings Citation Index-Science (CPCI-S), Conference Proceedings Citation Index-Social Science and Humanities (CPCI-SSH), and Emerging Source Citation Index (ESCI).

It is important to note that the searching strategy directly affects the results; the searching terms "eye tracking" or "eye movement" generate 40,601 records. As eye movement research in cartography is just one application of eye tracking technology, a narrower search scope is needed. Therefore, we further refined the results with searching terms such as "cartographic", "cartography", "map design", "map symbol", "map reading", "map display", "map usability", "map perception", "spatial cognition", "geovisualization", "spatial visualization", "web map", and "GIS", and refined the document type as article, book chapter, and proceeding papers. Our purpose is to obtain the research achievements about cartography problems solving based on eye movement analysis, rather than eye tracking technique itself. Finally, we obtained 209 bibliographic records with 7355 citations from the publication years 1984-2015. These publications are mainly published in Experimental Brain Research, Cartographic Journal, Cartography and Geographic Information Science, International Journal of Geographic Information Science, Journal of Eye Movement Research, and GeoConference on Informatics, Geoinformatics and Remote Sensing, etc. The data were retrieved on 10 January 2016 and updated on 2 August 2016. Since eye movement research in cartography is a burgeoning new area, we believe that sample bibliographic records are adequate.

The reason to choose WOS is because its authority and high quality. However, WOS does not index all scientific publications, especially for some workshops (e.g., International Workshop on Eye Tracking for Spatial Research), so we manually captured that workshop's papers and wrote the corresponding information into WOS format. Although the refining terms may not cover all aspects of cartography research, the method used in this paper is generally applicable [27]; researchers can restrict or expand the search scope according to their research interest.

\subsection{Workflow}

The workflow of our analysis process is shown in Figure 1. At the beginning, we extracted bibliographic records from WOS using the proper searching terms, and stored the data into text format. Then we conducted the following analysis: firstly, we used co-citation analysis to explore classic literature; next, we performed bibliographic coupling analysis to detect research theme clusters; then we employed co-occurrence analysis to identify research hotspots and generated collaboration networks at author-level and institution-level, as well as a geo-collaboration network based on the geovisualization method. Some skills should be needed to manipulate the network for better interpretation that will be discussed in Section 5 .

In the process, geovisualization is a key step to explore the spatial distribution and connection of scientific power. Geovisualization comprises the theory, methods, and tools for visual exploration, analysis, synthesis, and presentation of geospatial data. It draws on and integrates approaches from visualization in scientific computing, information visualization, cartography, image analysis, exploratory data analysis, and GIS [47]. Although the original bibliographic records are not geospatial data, we can extract the location-based information from text-format bibliographic records. For example, for data captured from WOS, the location-based information is stored in the $\mathrm{C} 1$ tag as the address string (e.g., BOSTON UNIV, CTR ADAPT SYST, 111 CUMMINGTON ST, BOSTON, $M A$ 02215). If we want to construct the city collaboration network, we can extract the city name $(B O S T O N)$ from the address string. As a paper may have multiple authors, there may be several addresses; therefore, the duplicated city names should be removed. Then, city names can be parsed by a geocoding service to obtain the longitude and latitude to construct points. If there are two cities associated with one paper, a line connecting the two points will be generated to represent the collaboration between the two cities. The relationship can be mapped with a graph $\mathrm{Gc}=(\mathrm{Vc}, \mathrm{Ec})$, in which $V_{c}$ are the city nodes and Ec are edges representing the collaboration of the cities. The process 
of constructing a geo-collaboration network is shown in Figure 2 and the pseudocode is presented in Appendix A.

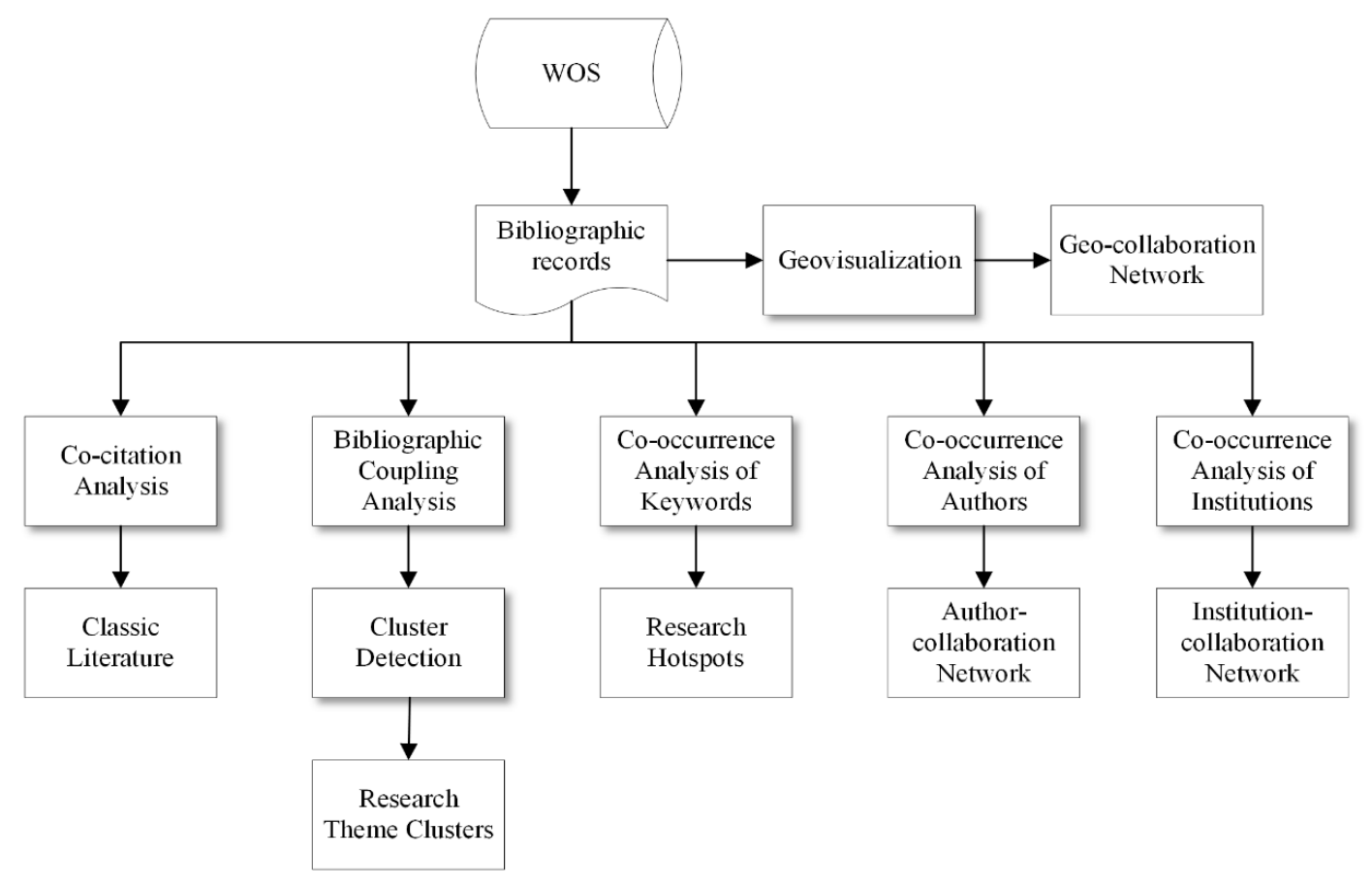

Figure 1. Workflow of the analysis process.

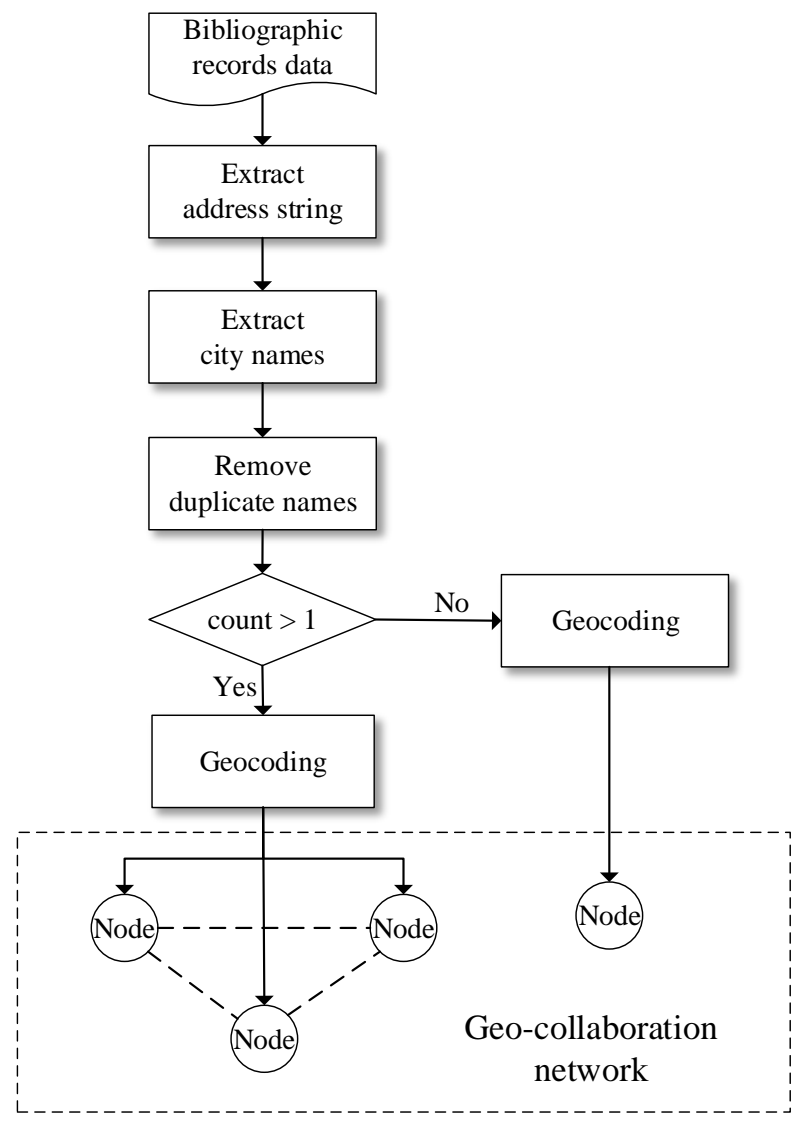

Figure 2. Process of constructing a geo-collaboration network. 


\subsection{Visualization Tools}

\subsubsection{Gephi}

Gephi is an open-source software for data analysts and scientists keen to explore and visualize graphs and networks [48]. It can produce a better representation output than CiteSpace and provide many network layout styles; for example, force atlas, fruchterman reingold, yifan hu, and geolayout. Since graphs created by CiteSpace may overlap (and, therefore, are sometimes hard to understand), we prefer to use Gephi to display networks by reading the exchange file with CiteSpace output.

In addition to its powerful graphical representation, Gephi is useful for exploratory data analysis. It can also detect community, and calculate the shortest path, degree centrality, betweenness centrality, clustering coefficients, and other information in the network.

\subsubsection{CartoDB}

CartoDB is an easy-to-use online geovisualization tool that allows the creation of beautiful visualizations of geographic data [49]. CartoDB can read user's data files or connect with Google Drive, Dropbox, or Twitter. It can create maps in seconds, and there is no need for users to install any additional software or have map-making experience. CartoDB APIs can provide more data processing and spatial analysis functionalities for developers.

\section{Results and Analysis}

\subsection{Classic Literature}

The term "classic literature" used here is defined as the most cited works by peers in one research field, that is, the works with high local citation score (LCS). The LCS is a more direct measure of specialty activity and profile because it reflects the topic/subject matter within the research domain [50]. Document co-citation analysis of all citations in bibliographic records reveals the most cited works. In CiteSpace, we performed document co-citation analysis of all the citations and displayed the results using a time zone view, as shown in Figure 3. The $x$-axis is divided into several zones by five-year intervals. In the figure, each node represents one work, which is comprised with rings; the color of the ring represents the year when the work was cited corresponding to the color ramp at the bottom of the figure, and the thickness of the ring represents its citation frequency. A line connecting two nodes indicates the co-citation relationship of the two works; the line color indicates the first time the two works were co-cited, which also corresponds to the color ramp. The top classic works identified in this analysis are labeled in Figure 3 and listed in Table 1, ordered by local citation score. In Table 1, the column "In Paper Collection" indicates that this work is also included in the bibliographic records download from WOS.

As illustrated in Figure 3, the earliest work is the book How people look at pictures [51], written by Buswell, a professor of educational psychology at the University of Chicago. This book is the first comprehensive publication to investigate and analyze subjects' eye movement behaviors while they looked at complex scenes. Buswell eye-tracked more than 200 subjects and used 55 photographs as experimental stimuli, including paintings, tapestries, and architecture [52]. Although this research applied eye movement analysis to psychology, and used photographs rather than maps as experimental stimuli, the photographs stimuli have some characteristics in common with maps [53], so these findings are important for cartography research. The citing relationships of this book mostly appeared before the 1980s; since that time, there has been much research on eye movement in cartography. 


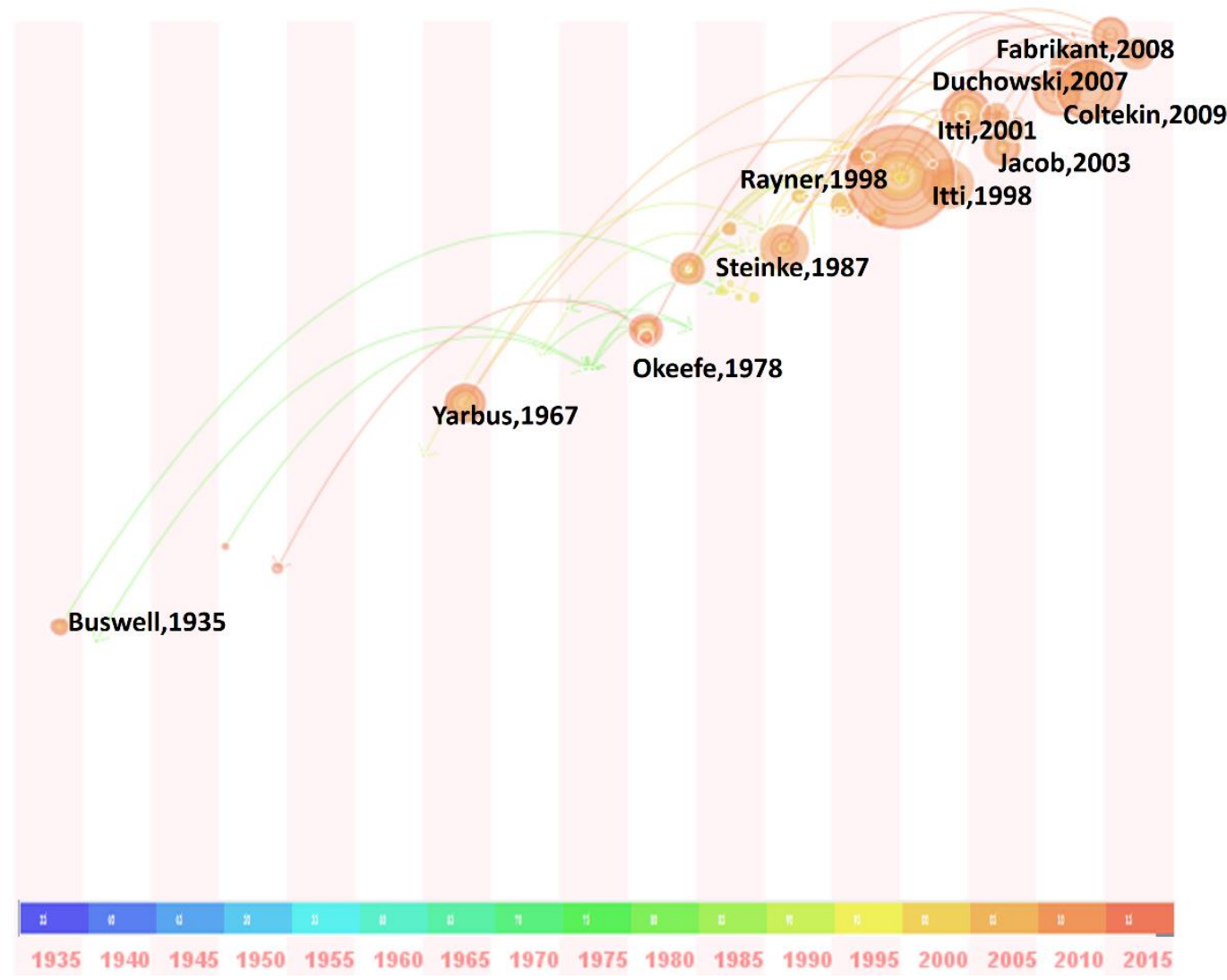

Figure 3. Classic works displayed using the time zone view.

Table 1. Top 10 classic literature identified using co-citation analysis.

\begin{tabular}{|c|c|c|c|c|}
\hline $\begin{array}{l}\text { First } \\
\text { Author }\end{array}$ & Year & Title & Local Citation Score & $\begin{array}{l}\text { In Citing Paper } \\
\text { Collection }\end{array}$ \\
\hline Rayner & 1998 & $\begin{array}{l}\text { Eye movements in reading and information } \\
\text { processing: } 20 \text { years of research }\end{array}$ & 27 & No \\
\hline Coltekin & 2009 & $\begin{array}{l}\text { Evaluating the effectiveness of interactive map } \\
\text { interface designs: A case study integrating } \\
\text { usability metrics with eye-movement analysis }\end{array}$ & 15 & Yes \\
\hline Itti & 1998 & $\begin{array}{l}\text { A model of saliency-based visual attention for } \\
\text { rapid scene analysis }\end{array}$ & 13 & No \\
\hline Itti & 2001 & Computational modelling of visual attention & 13 & No \\
\hline Fabrikant & 2008 & $\begin{array}{l}\text { Novel method to measure inference affordance } \\
\text { in static small-multiple map displays } \\
\text { representing dynamic processes }\end{array}$ & 13 & Yes \\
\hline Steinke & 1987 & $\begin{array}{l}\text { Eye movement studies in cartography and } \\
\text { related fields }\end{array}$ & 12 & No \\
\hline Duchowski & 2007 & Eye tracking methodology: Theory and practice & 12 & No \\
\hline Yarbus & 1967 & Eye motion and vision & 11 & No \\
\hline Jacob & 2003 & $\begin{array}{l}\text { Eye tracking in human-computer interaction and } \\
\text { usability research: ready to deliver the promises }\end{array}$ & 10 & No \\
\hline Okeefe & 1978 & The hippocampus as a cognitive map & 9 & No \\
\hline
\end{tabular}

The article Eye movement studies in cartography and related fields by Steinke [53] is a milestone for cartographers doing research on eye movement. In this article, Steinke reviewed lots of key works dealing with eye movement research in cartography and related fields, for example, the works did 
by Buswell and Brandt. Steinke highlighted the work of Jenks, who conducted many eye movement experiments since 1971 to address cartographers' questions about the relationships between map design and map reading.

The most significant node in Figure 3 is Rayner's article Eye movements in reading and information processing: 20 years of research, which reviewed eye movement studies in reading and other areas of information processing from 1978 to 1998 [54]. The second most significant node is Evaluating the effectiveness of interactive map interface designs: A case study integrating usability metrics with eye-movement analysis [17], published in Cartography and Geographic Information Science, which is one of the most authoritative accounts of map usability research. Using two interactive map websites, Coltekin et al. integrated eye movement research with traditional usability methods to measure the user satisfaction, efficiency, and effectiveness of the two map interfaces. Another usability study was Jacob and Karn's Eye tracking in human-computer interaction and usability research: ready to deliver the promises, which discussed both retrospective and real-time eye tracking in human-computer interaction [55]. Other remarkable works include: Itti et al. [56,57] proposed the saliency map model; Fabrikant et al. [58] introduced sequence alignment analyses techniques from bioinformatics to eye tracking recording data analysis. Additionally, there are three books listed in Table 1: Eye tracking methodology: Theory and practice [1]; Eye motion and vision [59]; and The hippocampus as a cognitive map [60]. Among them, Duchowski's book has been widely quoted and translated into Chinese; it systematically introduces the human visual system, the hardware and software of the eye tracking technique, and experimental guidelines for the use of eye tracking in many application areas.

\subsection{Research Theme Clusters}

In addition to retrospectively analyzing the classic literature of intellectual bases, we can use bibliographic coupling analysis to identify the latest literature to reveal developmental trends. It is possible to perform bibliographic coupling analysis on citing papers based on one or several classic works, and then cluster the network to extract research themes from paper titles, keywords, or abstracts which has been described in Section 2. In Table 1, we can find that Coltekin's work Evaluating the effectiveness of interactive map interface designs: A case study integrating usability metrics with eye-movement analysis is not only in Top 10 classic literature list, but also in the citing paper collection, and it is a representative of combining traditional usability metrics with eye movement research. Thus, we take Coltekin's work for example, and collected all 36 papers citing this work from WOS. The data was retrieved on 27 January 2016, the publication year spans from 2009 to 2015. The cluster result of the bibliographic coupling analysis is shown in Figure 4.

The bibliographic coupling network is divided into six clusters differentiated by color. The nodes are labeled with each paper's first author name and publication year, and the node size indicates its significance (i.e., degree centrality) in the network; that is, those nodes that have more connections with other nodes. The results show that the connections between the nodes are tight inside the clusters but loose between the clusters, and papers written by the same author or authors from the same institution are mostly clustered into one group. Both of these aspects indicate the rationality of the cluster result. The cluster partition can also be evaluated by silhouette, which is a homogeneity metric that ranges from -1 to 1 [61]. Generally, the result is significant when the silhouette is larger than 0.7 ; the larger the silhouette, the more homogeneous the cluster. As shown in Table 2, all the silhouettes are larger than 0.8 , so the result is confidential. Table 2 also shows the cluster labels extracted by tf*idf, LLR, and MI algorithms from paper titles. 


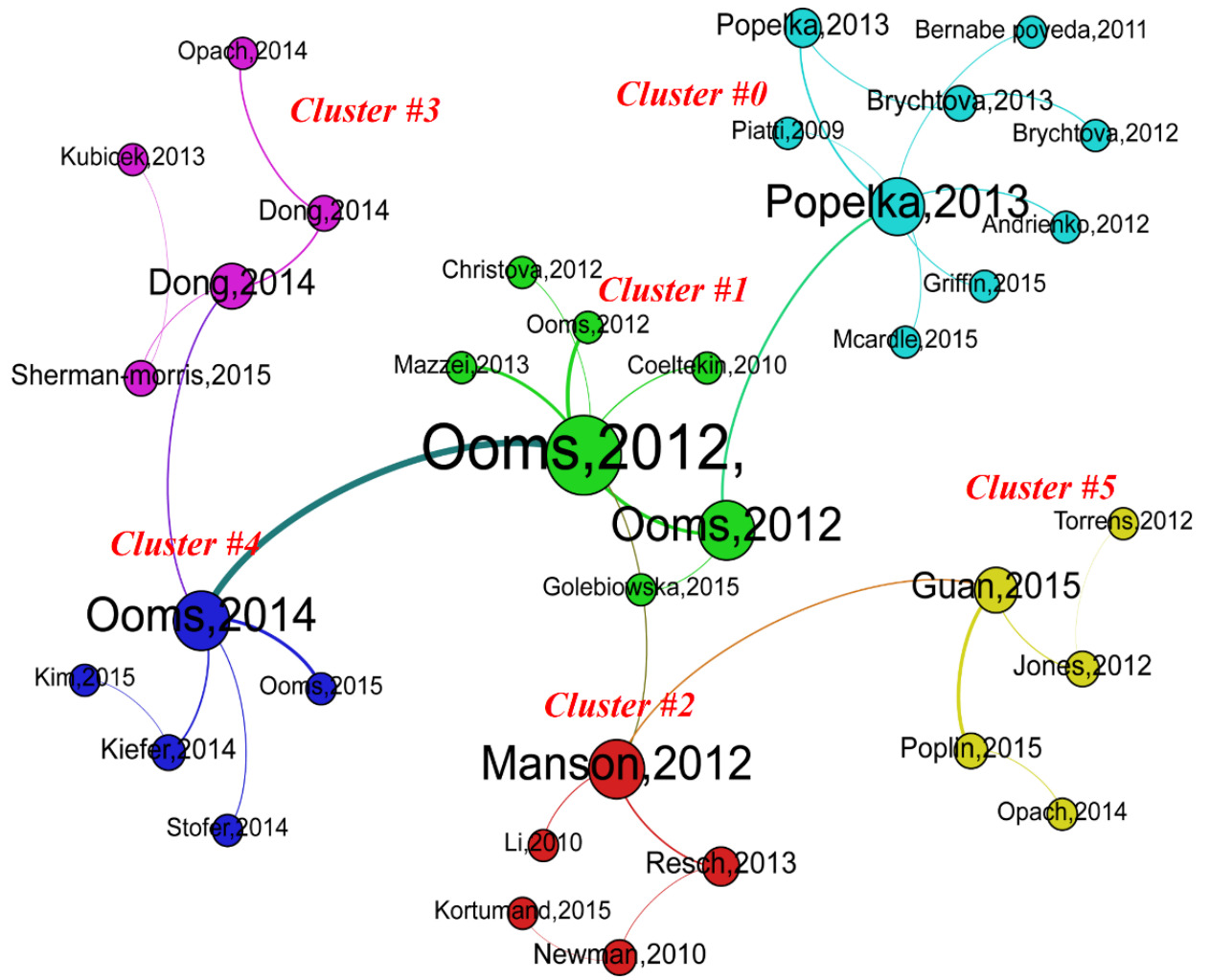

Figure 4. Clusters generated by bibliographic coupling analysis (size of the node represents its degree centrality in the network).

Table 2. Labels for clusters generated by different term ranking algorithms.

\begin{tabular}{|c|c|c|c|c|c|}
\hline $\begin{array}{l}\text { Cluster } \\
\text { ID }\end{array}$ & $\begin{array}{l}\text { Cluster } \\
\text { Size }\end{array}$ & Silhouette & tf ${ }^{*}$ idf (Weighting) & LLR (log-Likelihood Ratio, $p$ Value) & MI \\
\hline 0 & 9 & 0.947 & method (2.87) & $\begin{array}{l}\text { technique }(38.74,1.0 \mathrm{E}-4) \\
\text { highlighting relief }(38.74,1.0 \mathrm{E}-4) ; \\
\text { eye movement studies }(38.74,1.0 \mathrm{E}-4)\end{array}$ & eye \\
\hline 1 & 7 & 0.834 & $\begin{array}{l}\text { eye movement data } \\
(2.87) ; \text { method }(2.87)\end{array}$ & $\begin{array}{l}\text { exploring small city map } \\
(40.0,1.0 \mathrm{E}-4) ; \text { integrating usability } \\
\text { metric }(40.0,1.0 \mathrm{E}-4) \text {; thematic map } \\
(40.0,1.0 \mathrm{E}-4)\end{array}$ & eye movement data \\
\hline 2 & 5 & 0.883 & $\begin{array}{l}\text { web mapping ( } 2.87) \\
\text { usability }(0.52)\end{array}$ & $\begin{array}{l}\text { usability }(64.99,1.0 \mathrm{E}-4) \text {; user } \\
\text { experience design }(45,1.0 \mathrm{E}-4) \text {; } \\
\text { lesson }(45,1.0 \mathrm{E}-4)\end{array}$ & eye movement data \\
\hline 3 & 5 & 0.868 & eye tracking (2.87); & $\begin{array}{l}\text { people }(47.31,1.0 \mathrm{E}-4) ; \\
\text { visualization }(47.31,1.0 \mathrm{E}-4) ; \\
\text { web mapping } 47.31,1.0 \mathrm{E}-4)\end{array}$ & using eye tracking \\
\hline 4 & 5 & 0.851 & $\begin{array}{l}\text { eye tracking }(3.55) \\
\text { expert }(2.87) \\
\text { novice }(2.87)\end{array}$ & $\begin{array}{l}\text { novice }(81.11,1.0 \mathrm{E}-4) ; \text { dynamic } \\
\text { application }(41.44,1.0 \mathrm{E}-4) ; \\
\text { transfer }(41,44.0 \mathrm{E}-4)\end{array}$ & using eye tracking \\
\hline 5 & 5 & 0.93 & $\begin{array}{l}\text { survey (4.42); } \\
\text { understanding (4.42) }\end{array}$ & $\begin{array}{l}\text { heterogeneous user } \\
(43.08,1.0 \mathrm{E}-4) \text {; online interactive } \\
\text { map }(43.08,1.0 \mathrm{E}-4) \text {; choropleth map } \\
(43.08,1.0 \mathrm{E}-4) \text {; }\end{array}$ & $\cdots$ \\
\hline
\end{tabular}

If the number of clusters is too large, the cluster labeling method is much more useful to facilitate interpretation of the research themes. However, there is no precise way of determining which term ranking algorithm is best. If we are interested in usability research, cluster 1 and cluster 2 should both be further investigated. To examine the research theme of one cluster, it is useful to identify the papers with high degree centrality. By further exploring the high degree centrality papers, we can 
determine that in cluster 1 , the usability metric is mainly used for traditional cartography problems, for example, Ooms [62] proposed an improved label placement method based on eye movement analysis; Golebiowska [63] integrated usability metric to explore how map legend works as map is read; or using the Visual Analytics Toolkit for complementing conventional eye movement data analysis method [64]. In cluster 2, the usability research achievements are mainly related to new and emerging technologies like web mapping navigation schemes [20], citizen-based web mapping [65], mobile phone or tablet [66], or user experience in map-based geo-portals [67]. An examination of other clusters also reveals some interesting research topics, such as studies of perception of 2D and 3D terrain visualization [68], difference of experts and novices attentive behavior [12,13], animated maps [15,16], image enhancement in web mapping [69], and volunteered geographic information (VGI) [19].

\subsection{Research Hotspots}

By performing co-occurrence analysis of all the keywords extracted from bibliographic records (e.g., co-words analysis), we can create a co-occurrence network of keywords, as shown in Figure 5. This helps to detect the top ranked keywords with large node sizes, reflecting the research hotspots. The edges between two nodes represent the two keywords' co-occurrence relationship in one paper; nodes that have more connections with others (i.e., high degree centrality) are more significant in the network. For better interpretation, we excluded keywords like "eye movement" or "eye tracking", which are definitely the largest nodes in the network.

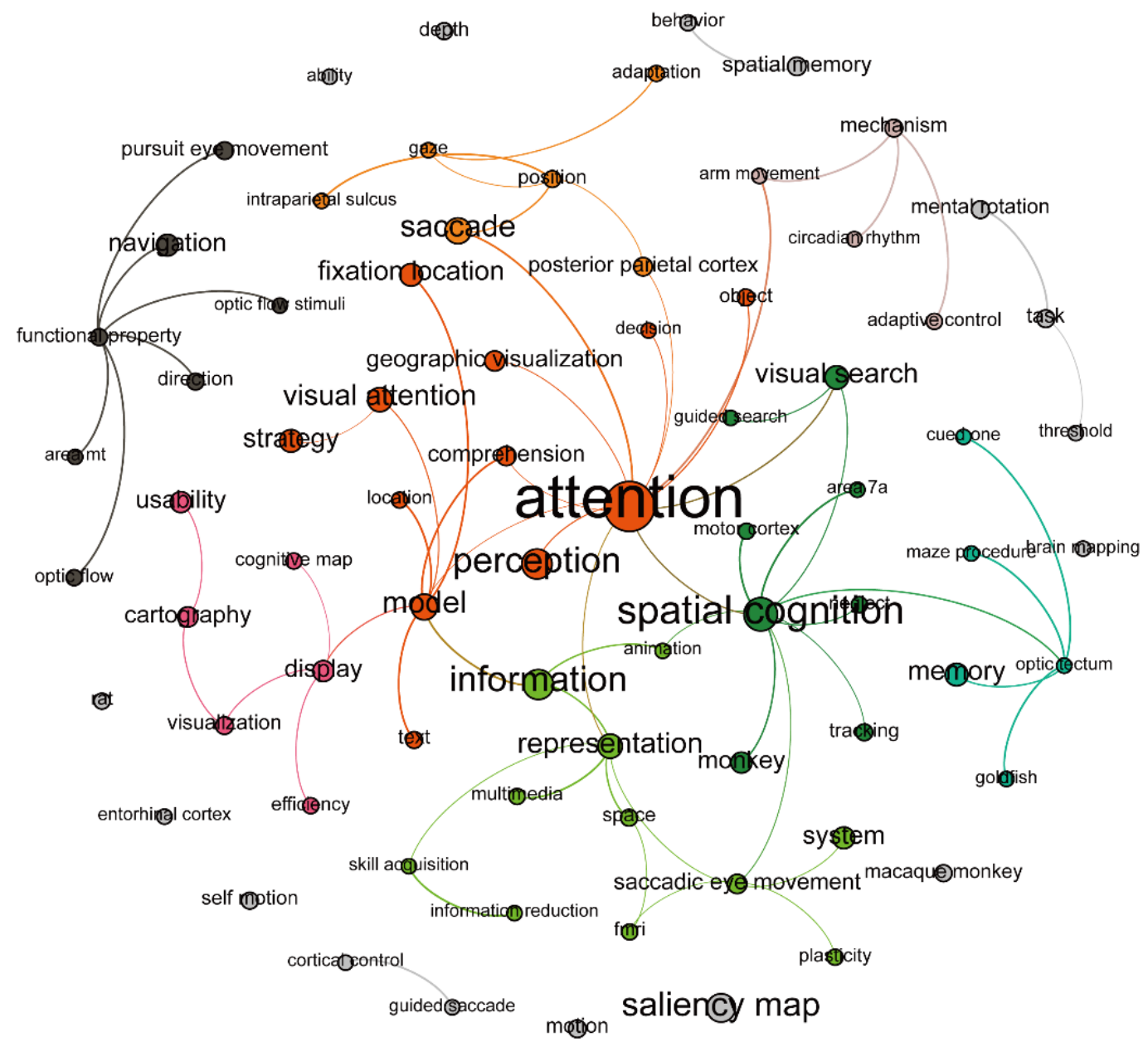

Figure 5. Co-occurrence network of keywords (size of the node represents its occurrence frequency in the network). 
As shown in Figure 5, "attention" and "spatial cognition" are the two major nodes in the network, both with high occurrence frequency and degree centrality. The Top 20 ranked keywords are listed in Table 3, ordered by occurrence frequency. It is interesting that the top ranked keywords ("visual attention", "visual search", "saccade", "perception", "strategy", "model", etc.) cluster mostly around these two significant nodes. Among them, "posterior parietal cortex", "perception", and "saccade" are related to "attention"; while "monkey", "area7a", and "memory" are located near "spatial cognition".

Table 3. Top 20 ranked keywords.

\begin{tabular}{cccccc}
\hline No. & Keyword & Frequency & No. & Keyword & Frequency \\
\hline 1 & attention & 44 & 11 & strategy & 12 \\
2 & spatial cognition & 24 & 12 & memory & 11 \\
3 & information & 20 & 13 & fixation location & 11 \\
4 & perception & 20 & 14 & system & 10 \\
5 & saliency map & 18 & 15 & navigation & 10 \\
6 & model & 15 & 16 & usability & 9 \\
7 & saccade & 15 & 17 & monkey & 9 \\
8 & visual attention & 13 & 18 & display & 9 \\
9 & representation & 13 & 19 & geographic visualization & 8 \\
10 & visual search & 12 & 20 & cartography & 8 \\
\hline
\end{tabular}

\subsection{Collaboration Patterns}

\subsubsection{Author Level}

Research collaboration is an activity engaged in by researchers working together for the common goal of producing new scientific knowledge, and co-authored publication has generally been used as a fundamental counting unit to measure this activity [70]. Price and Beaver [71] have pointed out that the invisible college comprised of highly productive authors is the main reason for rapid growth of knowledge. It is possible to detect co-author relationships and high productivity authors by generating a co-occurrence network of authors from the bibliographic records. Using this method, we found that nearly $80 \%$ of authors have only one publication. To highlight the main structure of the network, we excluded authors with only one publication from the network; the resultant structure is shown in Figure 6. The size of nodes represents the frequency (i.e., the author's publication quantity), and the lines connecting the nodes indicate the co-author relationships.

In Figure 6, it can be found that the most productive author is Popelka, who is the head of the eye tracking laboratory at Palacky University, Czech Republic. Popelka and his partner Brychtova have co-authored four works. Another significant group is led by Ooms, Maeyer, and Fabrikant. Ooms and Maeyer are from Ghent University, and they have co-authored eight works; Fabrikant is from Zurich University, who also has eight works, and we can see that there is a lot of cooperation between the two universities. Additionally, the team led by Callet and Narwaria is also outstanding, and there are four works co-authored by them. Table 4 shows the top ranked authors with more than three publications listed by publication quantity. In addition, it is important to notice that co-occurrence analysis of authors just use publication quantity as the nodes frequency. Unlike the H-index, it can only reflect the authority of scholars to some extent, and some prominent authors may not appear in this analysis result due to the fact that WOS does not index all publications in this research field. 


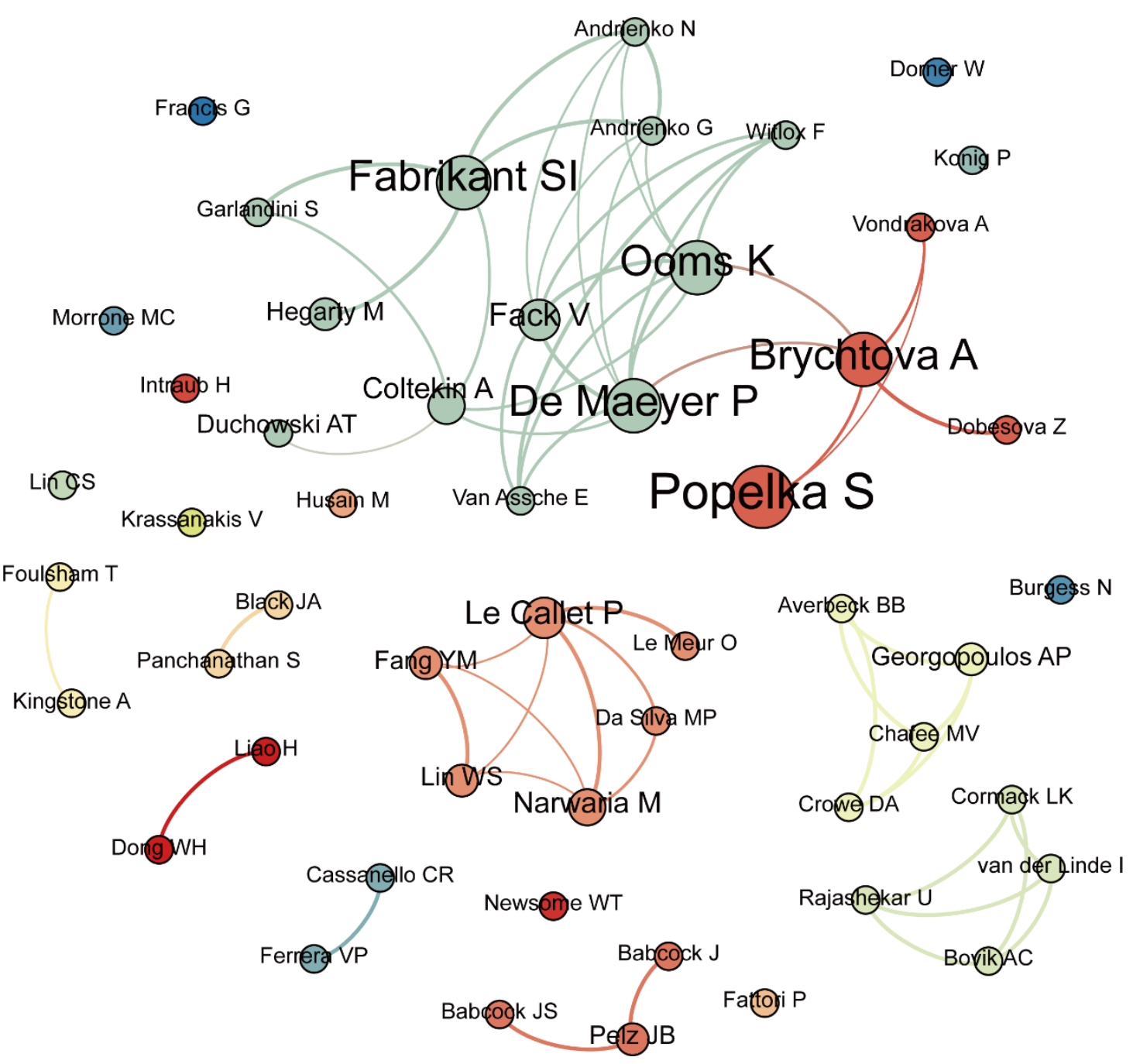

Figure 6. Co-occurrence network of authors (size of the node represents author's publication quantity).

Table 4. Top ranked authors.

\begin{tabular}{cccc}
\hline No. & Author & Frequency & As First Author Frequency \\
\hline 1 & Stanislav Popelka & 10 & 8 \\
2 & Alzbeta Brychtova & 8 & 3 \\
3 & Kristien Ooms & 8 & 6 \\
4 & Philippe De Maeyer & 8 & 0 \\
5 & Sara Irina Fabrikant & 8 & 3 \\
6 & Veerle Fack & 5 & 0 \\
7 & Patrick Le Callet & 5 & 0 \\
8 & Manish Narwaria & 4 & 2 \\
9 & Arzu Coltekin & 4 & 2 \\
\hline
\end{tabular}

\subsubsection{Institution Level}

The co-occurrence analysis of institutions can detect and visualize the distribution of scientific power. Figure 7 shows the main structure of the co-occurrence network of institutions after excluding institutions with only one publication. The node size represents the frequency (i.e., the institution's publication quantity), and the lines connecting nodes indicate the collaboration relationships between two institutions. The result indicates that collaboration always occurs between institutions with high publication quantity, such as Palacky University, Zurich University, and Ghent University, which form 
the core centers of the network. Minnesota University is also a significant node in the network. Other institutions with more than three publications are listed in Table 5.

Table 5. Top ranked institutions.

\begin{tabular}{ccc}
\hline No. & Institution & Frequency \\
\hline 1 & Palacky University & 16 \\
2 & Zurich University & 12 \\
3 & Ghent University & 8 \\
4 & Minnesota University & 6 \\
5 & University College London (UCL) & 5 \\
6 & Nottingham University & 5 \\
7 & Tubingen University & 5 \\
8 & Stanford University & 4 \\
9 & University of California, Santa Barbara & 4 \\
\hline
\end{tabular}

Univ London Imperia_Ooll Sci Technol\& Med

Univ œelaware NTOorp

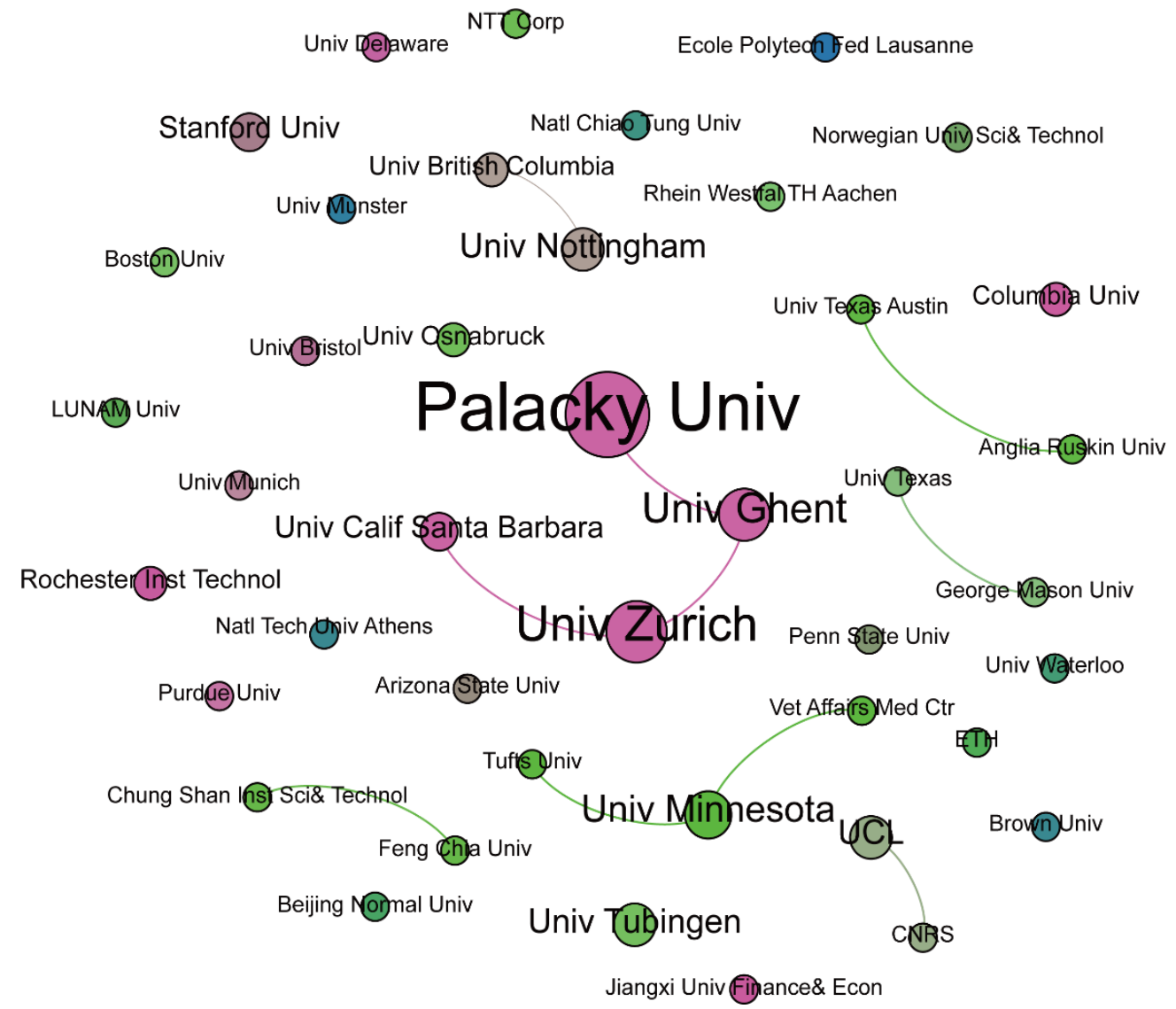

Figure 7. Co-occurrence network of institutions (size of the node represents institution's publication quantity).

In the process of generating co-occurrence networks of institutions, problems stemming from alternative spellings of an institution's name may be encountered. For example, in the bibliographic records, Palacky University is written as both "Palacky Univ" and "Palacky Univ Olomouc", two types of spelling that would create two nodes in the network. As a result, we have to merge the two nodes to avoid misinterpretation. Another problem is due to information missing of some author's institutions in bibliographic records, so these institutions' corresponding frequency would not be calculated. 


\subsubsection{City Level}

Geovisualization can display geospatial data interactively and dynamically to reveal the distribution of spatial phenomena. After extracting city location information from text-format bibliographic records, we constructed a geo-collaboration network at city level, as described in Section 3.2. CartoDB was used to make an interactive dot map as illustrated in Figure 8 to reveal the spatial distribution of scientific power. On the map, a dot represents a city where author's institution located in, and the line between two dots indicates two cities' cooperation relationship. It can be found that dots are clustered in Europe and USA, which forms two centers of eye movement research in cartography. The geo-collaboration network clearly shows that Europe is the international collaboration center in the world. GIS statistics indicate that nearly $60 \%$ of the city collaboration relationships are transnational collaborations, and the average collaboration distance is $2300 \mathrm{~km}$, which indicates how international collaboration is more convenient in modern times owing to progress in transportation and academic communications.

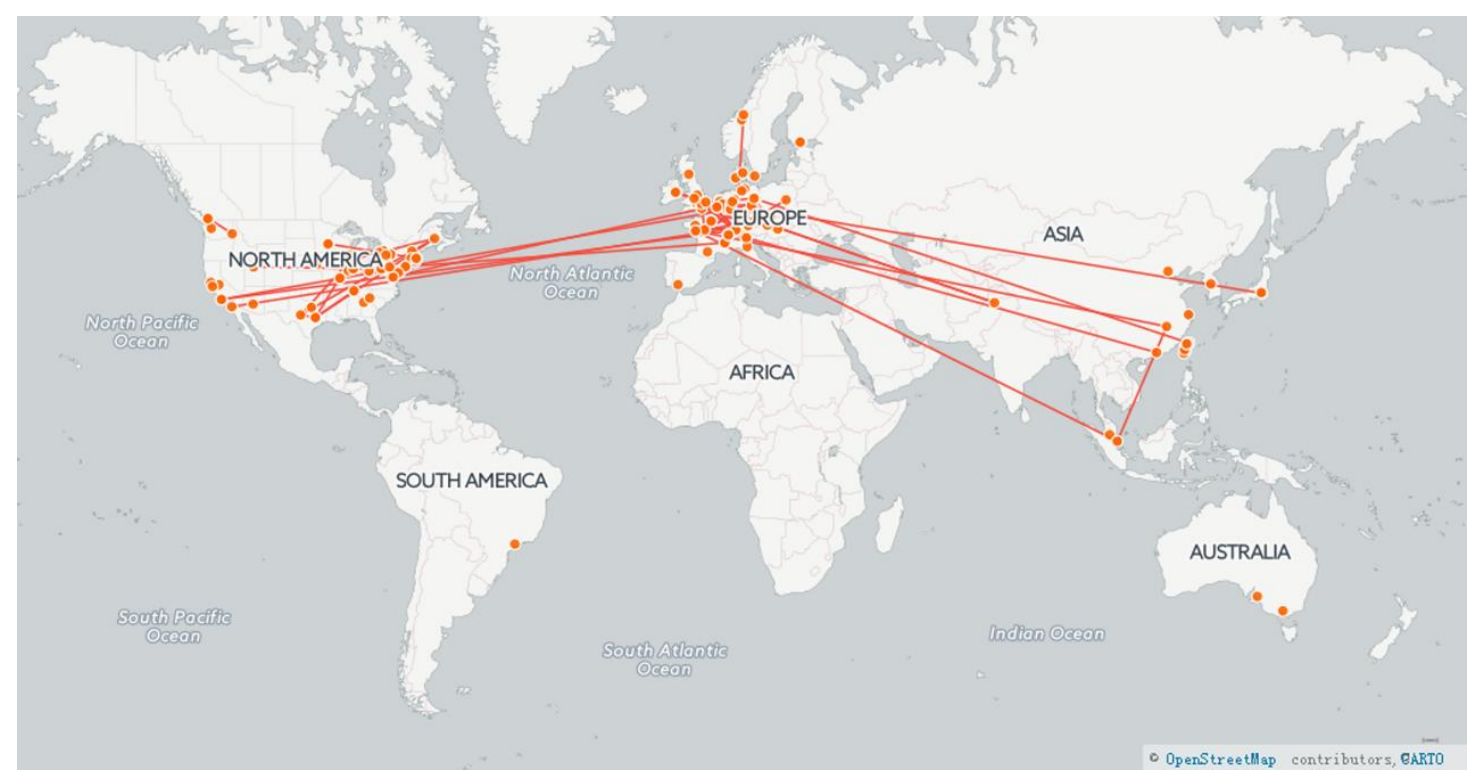

Figure 8. Geovisualization of scientific collaboration.

\section{Discussion}

\subsection{Discussion Related to Analysis Methods}

By introducing the use of bibliometric analysis methods in eye movement research in cartography, this paper demonstrates an effective and efficient way to visualize the intellectual structure of this knowledge domain, helping researchers quickly discover the main structure of this burgeoning research field. In addition, we did a lot of work that would improve current methods to facilitate interpretation from a professional perspective, greatly contributing to better understanding of the results. Four facets of the work warrant discussion.

First, the searching strategy is key to the results, so the proper searching strategy should be discussed with experts on this field, and may be modified several times based on results evaluation. On the other hand, due to the fact that WOS does not index all scientific publications, it is difficult to fully encompass the research scope of this field. Therefore, we manually added some workshop papers to ensure the effectiveness of the results, but it is time consuming. The automatic mechanism to translate the user-defined bibliographic database format into WOS format is needed, but it is a challenging work due to different standards of different databases. 
Second, the selection criteria for network construction is key to controlling the scope of the network model. For example, there are several methods to select criteria in the network, such as Top N, Top N\%, and threshold levels of c, cc, ccv (i.e., citation threshold, co-citations threshold, co-citation coefficients threshold) [34] for each time slice. Considering the quantity of publications and the year span in our bibliographic records, we chose the Top $\mathrm{N}$ method and set it as 10, with five years as the time interval for co-citation analysis, as well as Top 10 for bibliographic coupling analysis, Top 50 for co-occurrence of keywords, authors, and institutions of each year. Large data sets permit larger $\mathrm{N}$ values.

Third, the network should be manipulated after generation to achieve better interpretation. Take the co-occurrence of keywords as an example. If the largest nodes "eye movement" and "eye tracking", which are definitely prominent, are not excluded from the network, other nodes may appear very small and be difficult to identify. In some cases, nodes should be merged because of different spellings of the same object, such as institution or author names.

Finally, since the visualization outputs generated by bibliometric analysis tools are not very satisfactory, it is a better choice to present the analysis results by other visualization tools, such as Gephi, based on exchange files. Additionally, by constructing a geo-collaboration network, the distribution of scientific power was represented at a macro level. This allowed us to extract location-based information from bibliographic records and display it spatially and intuitively. Furthermore, more GIS functionalities, such as spatial clustering analysis, can be performed.

\subsection{Discussion Related to Current Trends}

In addition to the WOS literature, some workshops have contributed much to the development of eye movement research in cartography, for instance, the pre-conference workshop on eye tracking sponsored by ICA (International Cartographic Association) in 2013, and the 1st and 2nd International Workshop on Eye Tracking for Spatial Research held in 2013 and 2014. During the ICA eye tracking workshop, in addition to applications of eye movement research, new measurements and GIS tools were introduced to analyze eye movement data (e.g., a method to automatically identify user's different activities on maps [72], using a space-time cube to display and analyze eye movement recordings [73,74]). ICA Commission on Cognitive Issues in Geographic Information Visualization also listed some tools for eye movement data analysis on its official website. EyeMMV (Eye Movements Metrics and Visualizations) and Saliency toolbox are the representative ones among them. EyeMMV is an open source MATLAB toolbox designed for post experimental eye movement analysis, which supports all eye tracking metrics and visualization techniques [75]. The project of saliency-based visual attention was started in the laboratory of Prof. Christof Koch at Caltech. The saliency toolbox is also a MATLAB toolbox that used for computing the saliency map of an image $[56,57,76,77]$. Additionally, other useful tools include iMap4 [78] and DynAOI [79]. The International Workshop on Eye Tracking for Spatial Research launched a wide range of discussion about eye movement research that is not limited to cartography. For example, with mobile eye tracker, both indoor and outdoor way-finding have been further discussed [80-83].

Recent technological developments in the area of eye movement have opened up new perspectives for cartographers in spatial cognition research. Cartographers have made many progresses on navigation behaviors with eye tracking techniques. By comparing 2D maps with photorealistic $3 \mathrm{D}$ representations for pedestrian navigation, Dong and Liao [84,85] found that the advantages and disadvantages of 3D representations are task dependent: 3D representations performed less effectively and efficiently in the process of spatial knowledge acquisition, but more efficiently in self-positioning and orientation. Similar experimentation was conducted by Lei et al. [86], using 2D and $3 \mathrm{D}$ electronic maps for way-finding. The results showed that people carried out a wider ranging search and shorter viewing time with the 2D electronic map, while the 3D electronic map provided more information about the environment. Additionally, mobile eye trackers have been adopted to evaluate landmark identification and recall on maps $[87,88]$. On the aspect of map reading and map 
perception, some special users (e.g., users with color vision deficiency) have been investigated [89]. Furthermore, compared with 2D static maps, dynamic map symbols [90,91], dynamic interactive applications [92-94], and panoramic maps [95] have attracted much more attention in cartographers. In the future, eye tracking techniques might make great contributions to cartography in the usability research of VR (virtual reality) [96], AR (augmented reality) [97], emotional recognition [98,99], etc.

\section{Conclusions}

This paper investigated and visualized the classic literature, research theme clusters, research thotspots, and collaboration patterns of eye movement research in cartography using multiple visual metaphors. In addition, geovisualization method was used to represent the spatial distribution of scientific power. As a result, we discovered some interesting characteristics of this knowledge domain.

Co-citation analysis revealed the classic literature that would be most helpful for novice researchers. The result showed that eye movement research in cartography is an interdisciplinary field that encompasses areas such as psychology, cognitive science, usability engineering, and computer science. Particularly at the early stage of its development, the most cited literature is from the psychology research field. Since the 1970s, some cartographers have explored relationships between map design and map reading using eye tracking experiments, and there has been much research since the 1980s, especially in the last two decades. The co-words analysis results showed that cartographers have focused on attention and spatial cognition, and bibliographic coupling analysis identified some trends of usability research. In addition to focusing on the classical problems in traditional cartography, such as the map labels placement method or map legend layout, eye movement research in cartography about usability has embraced several emerging techniques, such as web mapping, mobile mapping, animated mapping, and VGI.

This paper also explored scientific collaboration from a micro level to a macro level; this helped to reveal the authorities and scientific power distribution of this research field. We noted that most of the authors had only one publication; that the most productive authors are mainly from Palacky University, Zurich University, and Ghent University; and that highly productive authors always have more collaboration relationships. In addition, the geo-collaboration network showed that Europe and the USA form two clusters of eye movement research in cartography, and that Europe is the international collaboration center.

A picture is worth a thousand words and the method proposed in this paper may help the investigation of knowledge domains. We hope that the method will not only assist researchers in quickly grasping the evolution and trends of their research field, but will also become a novel method by which to merge geovisualization with knowledge visualization.

Acknowledgments: This research is supported by "National Natural Science Foundations of China (NSFC, Grant No. 41171353 and No. 41501507)", "Youth Science Funds of LREIS (Grant No. 08R8B6IOYA), CAS", "National High Technology Research and Development Program ("863"Program) of China (Grant No. 2012AA12A404)". Comments from reviewers are appreciated, which helped in the improvement of this article's quality.

Author Contributions: Shuang Wang drafted and finalized the manuscript. Yufen Chen revised the paper. Yecheng Yuan processed the data. Haiyun Ye and Shulei Zheng contributed to graph making and optimizing.

Conflicts of Interest: The authors declare no conflict of interest.

\section{Appendix A}

Program Geo-collaboration network

Dim record, addresscontext as String

Dim i, linenum as Integer

Dim isFindAddress as Boolean

//step 1: find the address 
isFindAddress $=$ false

linenum $=$ the line number of the record

For $i=1$ to linenum

If the line $i$ of the record is start with ' $\mathrm{Cl}$ ' // ' $\mathrm{Cl}$ ' is the tag of the address

for each author in one paper

addresscontext $=$ the context of the line $i$ of the record

isFindAddress = true

End if

If isFindAddress is true

Break for

Else

Continue

End if

End for

//step 2: find the city names in each address

Dim addresses, citynames as String list

Dim address, cityname as String

Dim $j$, addressnum as Integer

addresses = split (addresscontext, '.') // The address for each author is segmented by punctuation '.'

addressnum $=$ the number of the addresses

For $\mathrm{j}=1$ to addressnum

address $=$ addresses $[j]$

cityname = Second to last of split(address, ',') // The address is composed by state

name, street number, city name, post code etc. The city name is the second to last one.

Add cityname to citynames;

End for

//step 3: remove the duplicate in the city names

Dim k, citynamenum as Integer

Dim finalcitynames as String list

citynamenum $=$ the number of the citynames

For $\mathrm{k}=1$ to citynamenum

cityname $=$ citynames $[\mathrm{k}]$

if cityname is not in finalcitynames

Add cityname to finalcitynames

end if

End for

//step 4: Geocoding

Dim $m$, finalcitynamenum as Integer

Dim citycoordinate as Coordinate // The longitude and latitude of the city

Dim citycoordinates as Coordinate list

finalcitynamenum $=$ the number of the finalcitynames

For $m=1$ to finalcitynamenum

cityname $=$ finalcitynames $[\mathrm{m}]$

citycoordinate = GeocodingbyBing (cityname) //Getting the longitude and latitude of the city by geocoding service of Bing 


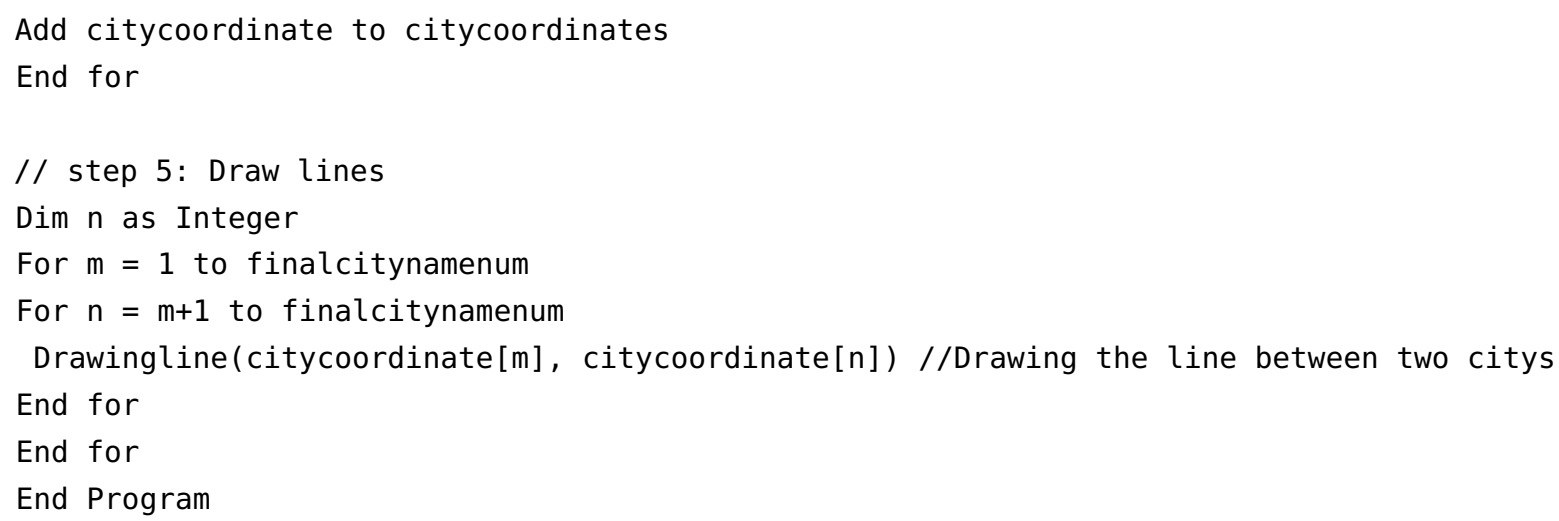

\section{References}

1. Duchowski, A.T. Eye Tracking Methodology: Theory and Practice; Springer: London, UK, 2007.

2. Castner, H.W.; Eastman, R.J. Eye-movement parameters and perceived map complexity-I. Am. Cartogr. 1984, 11, 107-117. [CrossRef]

3. Rayner, K.; Sereno, S.C.; Raney, G.E. Eye movement control in reading: A comparison of two types of models. J. Exp. Psychol. Human Percept. Perform. 1996, 22, 1188-1200. [CrossRef]

4. Slykhuis, D.A.; Wiebe, E.N.; Annetta, L.A. Eye-tracking students' attention to powerpoint photographs in a science education setting. J. Sci. Educ. Technol. 2005, 14, 509-520. [CrossRef]

5. Rayner, K.; Rotello, C.M.; Stewart, A.J.; Keir, J.; Duffy, S.A. Integrating text and pictorial information: Eye movements when looking at print advertisements. J. Exp. Psychol. Appl. 2001, 7, 219-226. [CrossRef] [PubMed]

6. Gorovaya, A.E.; Korobeinikova, E.Y. Use of eye-tracking technology in sport psychology. Psychol. Sci. Educ. 2013, 1, 1-16.

7. Victor, T.W.; Harbluk, J.L.; Engström, J.A. Sensitivity of eye-movement measures to in-vehicle task difficulty. Trans. Res. Part F Traffic Psychol. Behav. 2005, 8, 167-190. [CrossRef]

8. Duchowski, A.T. A breadth-first survey of eye-tracking applications. Comput. J. Psychon. Soc. 2002, 34, 455-470. [CrossRef]

9. Clifton, C.; Ferreira, F.; Henderson, J.M.; Inhoff, A.W.; Liversedge, S.P.; Reichle, E.D.; Schotter, E.R. Eye movements in reading and information processing: Keith rayner's 40 year legacy. J. Mem. Lang. 2015, 1-19. [CrossRef]

10. Brodersen, L.; Andersen, H.H.; Weber, S. Applying Eye-Movement Tracking for the Study of Map Perception and Map Design; Kort \& Matrikelstyrelsen: Copenhagen, Denmark, 2002.

11. Ooms, K.; De Maeyer, P.; Fack, V. Analyzing eye movement patterns to improve map design. In Proceedings of the 18th International Research Symposium on Computer-based Cartography and GIScience: Geospatial Data and Geovisualization for The Environments, Security, and Society, Orlando, FL, USA, 15-19 November 2010.

12. Stofer, K.; Che, X. Comparing experts and novices on scaffolded data visualizations using eye-tracking. J. Eye Mov. Res. 2014, 7, 1-15.

13. Ooms, K.; De Maeyer, P.; Fack, V. Study of the attentive behavior of novice and expert map users using eye tracking. Cartogr. Geogr. Inf. Sci. 2014, 41, 37-54. [CrossRef]

14. Montello, D.R. Cognitive map-design research in the twentieth century: Theoretical and empirical approaches. Cartogr. Geogr. Inf. Sci. 2002, 29, 283-304. [CrossRef]

15. Dong, W.H.; Liao, H.; Fang, X.U.; Liu, Z.; Zhang, S.B. Using eye tracking to evaluate the usability of animated maps. Sci. China-Earth Sci. 2014, 57, 512-522. [CrossRef]

16. Opach, T.; Gołębiowska, I.; Fabrikant, S.I. How do people view multi-component animated maps? Cartogr. J. 2014, 51, 330-342. [CrossRef]

17. Çöltekin, A.; Heil, B.; Garlandini, S.; Fabrikant, S.I. Evaluating the effectiveness of interactive map interface designs: A case study integrating usability metrics with eye-movement analysis. Cartogr. Geogr. Inf. Sci. 2009, 36, 5-17. [CrossRef] 
18. Ooms, K.; Andrienko, G.; Andrienko, N.; Maeyer, P.D.; Fack, V. Visual analytics on eye movement data reveal search patterns on dynamic and interactive maps. In Proceedings of the GeoCart 2010, CD Proceedings, Auckland, New Zealand, 1-3 September 2010.

19. Jones, C.E.; Weber, P. Towards usability engineering for online editors of volunteered geographic information: A perspective on learnability. Trans. GIS 2012, 16, 523-544. [CrossRef]

20. Manson, S.M.; Kne, L.; Dyke, K.R.; Shannon, J.; Eria, S. Using eye-tracking and mouse metrics to test usability of web mapping navigation. Cartogr. Geogr. Inf. Sci. 2012, 39, 48-60. [CrossRef]

21. Kiefer, P.; Raubal, M.; Straub, F. Location-aware mobile eye tracking for the explanation of wayfinding behavior. In Proceedings of the Agile 2012 International Conference on Geographic Information Science, Avignon, France, 24-26 April 2012.

22. Kiefer, P.; Giannopoulos, I.; Raubal, M. Where am i? Investigating map matching during self-localization with mobile eye tracking in an urban environment. Trans. GIS 2014, 18, 660-686. [CrossRef]

23. Chen, C.; Hu, Z.; Liu, S.; Tseng, H. Emerging trends in regenerative medicine: A scientometric analysis in citespace. Expert Opin. Biol. Ther. 2012, 12, 593-608. [CrossRef] [PubMed]

24. Wu, Y.; Duan, Z. Visualization analysis of author collaborations in schizophrenia research. BMC Psychiatr. 2015. [CrossRef] [PubMed]

25. Kim, M.C.; Chen, C. A scientometric review of emerging trends and new developments in recommendation systems. Scientometrics 2015, 104, 239-263. [CrossRef]

26. Qian, G.; Fong, M. Scientometrics analysis on the intellectual structure of the research field of bioenergy. J. Biobased Mater. Bioenergy 2013, 7, 305-308. [CrossRef]

27. Wei, F.; Grubesic, T.H.; Bishop, B.W. Exploring the gis knowledge domain using citespace. Prof. Geogr. 2015, 67, 374-384. [CrossRef]

28. Backhaus, K.; Kai, L.; Koch, M. The structure and evolution of business-to-business marketing: A citation and co-citation analysis. Ind. Mark. Manag. 2011, 40, 940-951. [CrossRef]

29. Huang, M.H.; Chiang, L.Y.; Chen, D.Z. Constructing a patent citation map using bibliographic coupling: A study of taiwan's high-tech companies. Scientometrics 2003, 58, 489-506. [CrossRef]

30. Yu, Q.; Shao, H.; Duan, Z. Research groups of oncology co-authorship network in china. Scientometrics 2011, 89, 553-567. [CrossRef]

31. Fan, Z.G.; Zheng, W.L. The analysis of research hotspot of chinese cultural and creative industry-based on co-words method. Adv. Mater. Res. 2013, 798-799, 924-929. [CrossRef]

32. Small, H. Co-citation in the scientific literature: A new measure of the relationship between two documents. J. Am. Soc. Inf. Sci. 1973, 24, 265-269. [CrossRef]

33. White, H.D.; Griffith, B.C. Author cocitation: A literature measure of intellectual structure. J. Am. Soc. Inf. Sci. 1981, 32, 163-171. [CrossRef]

34. Chen, $C$. Citespace ii: Detecting and visualizing emerging trends and transient patterns in scientific literature. J. Am. Soc. Inf. Sci. Tech. 2006, 57, 359-377. [CrossRef]

35. Appio, F.P.; Cesaroni, F.; Minin, A.D. Visualizing the structure and bridges of the intellectual property management and strategy literature: A document co-citation analysis. Scientometrics 2014, 101, 623-661. [CrossRef]

36. Özçınar, H. Mapping teacher education domain: A document co-citation analysis from 1992 to 2012. Teach. Teach. Edu. 2015, 47, 42-61. [CrossRef]

37. Kessler, M.M. Bibliographic coupling between scientific papers. Am. Doc. 1963, 14, 10-25. [CrossRef]

38. Boyack, K.W.; Richard, K. Co-citation analysis, bibliographic coupling, and direct citation: Which citation approach represents the research front most accurately? J. Am. Soc. Inf. Sci. Tech. 2010, 61, 2389-2404. [CrossRef]

39. Kostoff, R.N. Multidisciplinary research thrusts from co-word analysis. In Proceedings of the Technology Management: The New International Language, Portland, OR, USA, 27-31 October 1991.

40. He, Q. Knowledge discovery through co-word analysis. Libr. Trends 1999, 48, 133-133.

41. Liu, Z.; Yin, Y.; Liu, W.; Dunford, M. Visualizing the intellectual structure and evolution of innovation systems research: A bibliometric analysis. Scientometrics 2015, 103, 135-158. [CrossRef]

42. Cobo, M.J.; López-Herrera, A.G.; Herrera-Viedma, E.; Herrera, F. Science mapping software tools: Review, analysis, and cooperative study among tools. J. Am. Soc. Inf. Sci. Tech. 2011, 62, 1382-1402. [CrossRef] 
43. Chen, C.; Ibekwe-SanJuan, F.; Hou, J. The structure and dynamics of cocitation clusters: A multiple-perspective cocitation analysis. J. Am. Soc. Inf. Sci. Tech. 2010, 61, 1386-1409. [CrossRef]

44. Aizawa, A. An information-theoretic perspective of tf-idf measures. Inf. Process. Manag. Int. J. 2003, 39, 45-65. [CrossRef]

45. Dunning, T. Accurate methods for the statistics of surprise and coincidence. Comput. Linguist. 1993, 19, 61-74.

46. Latham, P.E.; Roudi, Y. Mutual information. Scholarpedia 2009, 125, 85-98. [CrossRef]

47. MacEachren, A.M.; Kraak, M.J. Research challenges in geovisualization. Cartogr. Geogr. Inf. Sci. 2013, 28, 3-12. [CrossRef]

48. Bastian, M.; Heymann, S.; Jacomy, M. Gephi: An open source software for exploring and manipulating networks. In Proceedings of the Third International AAAI Conference on Weblogs and Social Media, San Jose, CA, USA, 17-20 May 2009.

49. Zastrow, M. Data visualization: Science on the map. Nature 2015, 519, 119-120. [CrossRef] [PubMed]

50. Olijnyk, N.V. An algorithmic historiography of the ebola research specialty: Mapping the science behind ebola. Scientometrics 2015, 105, 623-643. [CrossRef]

51. Buswell, G.T. How People Look at Pictures; University of Chicago Press: Chicago, IL, USA, 1935.

52. Babcock, J.S.; Lipps, M.; Pelz, J.B. How people look at pictures before, during, and after scene capture: Buswell revisited. In Proceedings of the Electronic Imaging 2002, Santa Clara, CA, USA, 21-24 January 2002.

53. Steinke, T.R. Eye movement studies in cartography and related fields. Cartogr. Int. J. Geogr. Inf. Geovis. 1987, 24, 40-73. [CrossRef]

54. Rayner, K. Eye movements in reading and information processing: 20 years of research. Psychol. Bull. 1998, 124, 372-422. [CrossRef] [PubMed]

55. Jacob, R.; Karn, K.S. Eye tracking in human-computer interaction and usability research: Ready to deliver the promises. Mind 2003, 2, 573-605.

56. Itti, L.; Koch, C.; Niebur, E. A model of saliency-based visual attention for rapid scene analysis. IEEE Trans. Pattern Anal. Mach. Intell. 1998, 20, 1254-1259. [CrossRef]

57. Itti, L.; Koch, C. Computational modelling of visual attention. Nat. Rev. Neurosci. 2001, 2, 194-203. [CrossRef] [PubMed]

58. Fabrikant, S.I.; Rebich-Hespanha, S.; Andrienko, N.; Andrienko, G.; Montello, D.R. Novel method to measure inference affordance in static small-multiple map displays representing dynamic processes. Cartogr. J. 2008, 45, 201-215. [CrossRef]

59. Yarbus, D. Eye Motion and Vision; Plenum Press: New York, NY, USA, 1967.

60. O'keefe, J.; Nadel, L. The Hippocampus as a Cognitive Map; Oxford University Press: Oxford, OU, USA, 1978.

61. Rousseeuw, P.J. Silhouettes: A graphical aid to the interpretation and validation of cluster analysis. J. Comput. Appl. Math. 1987, 20, 53-65. [CrossRef]

62. Ooms, K.; Maeyer, P.D.; Fack, V.; Assche, E.V.; Witlox, F. Investigating the effectiveness of an efficient label placement method using eye movement data. Cartogr. J. 2012, 49, 234-246. [CrossRef]

63. Gołębiowska, I. Legend layouts for thematic maps: A case study integrating usability metrics with the thinking aloud method. Cartogr. J. 2015, 52, 28-40. [CrossRef]

64. Ooms, K.; Andrienko, G.; Andrienko, N.; De Maeyer, P.; Fack, V. Analysing the spatial dimension of eye movement data using a visual analytic approach. Exp. Syst. Appl. 2012, 39, 1324-1332. [CrossRef]

65. Newman, G.; Zimmerman, D.; Crall, A.; Laituri, M.; Graham, J.; Stapel, L. User-friendly web mapping: Lessons from a citizen science website. Int. J. Geogr. Inf. Sci. 2010, 24, 1851-1869. [CrossRef]

66. Kortum, P.; Sorber, M. Measuring the usability of mobile applications for phones and tablets. Int. J. Hum. Comput. Int. 2015, 31, 518-529. [CrossRef]

67. Resch, B.; Zimmer, B. User experience design in professional map-based geo-portals. ISPRS Int. J. Geo-Inf. 2013, 2, 1015-1037. [CrossRef]

68. Popelka, S.; Brychtova, A. Eye-tracking study on different perception of $2 \mathrm{~d}$ and $3 \mathrm{~d}$ terrain visualisation. Cartogr. J. 2013, 50, 240-246. [CrossRef]

69. Dong, W.H.; Liao, H.; Roth, R.E.; Wang, S.Y. Eye tracking to explore the potential of enhanced imagery basemaps in web mapping. Cartogr. J. 2014, 51, 313-329. [CrossRef]

70. Katz, J.S.; Martin, B.R. What is research collaboration? Res. Policy 1997, 26, 1-18. [CrossRef] 
71. Price, D.J.; Beaver, D.J. Collaboration in an invisible college. Am. Psychol. 1966, 21, 1011-1018. [CrossRef] [PubMed]

72. Kiefer, P.; Giannopoulos, I.; Raubal, M. Using eye movements to recognize activities on cartographic maps. In Proceedings of the 21st ACM SIGSPATIAL International Conference on Advances in Geographic Information Systems, Orlando, FL, USA, 5-8 November 2013.

73. Opach, T.; Rød, J.K. The Use of GIS Tools for Analyzing Eyemovement Data; TU Dresden: Dresden, Germany, 2013.

74. Kurzhals, K.; Weiskopf, D. Space-time visual analytics of eye-tracking data for dynamic stimuli. IEEE Trans. Vis. Comput. Graph. 2013, 19, 2129-2138. [CrossRef] [PubMed]

75. Krassanakis, V.; Nakos, B.; Filippakopoulou, V. Eyemmv toolbox: An eye movement post-analysis tool based on a two-step spatial dispersion threshold for fixation identification. J. Eye Mov. Res. 2014, 7, 1-10.

76. Itti, L.; Koch, C. A saliency-based search mechanism for overt and covert shifts of visual attention. Vis. Res. 2000, 40, 1489-1506. [CrossRef]

77. Itti, L.; Koch, C. Comparison of feature combination strategies for saliency-based visual attention systems. Int. Soc. Opt. Eng. 1999, 3644, 473-482.

78. Lao, J.; Miellet, S.; Pernet, C.; Sokhn, N.; Caldara, R. I map4: An open source toolbox for the statistical fixation mapping of eye movement data with linear mixed modeling. J. Vis. 2015, 15, 1-17. [CrossRef]

79. Papenmeier, F.; Huff, M. Dynaoi: A tool for matching eye-movement data with dynamic areas of interest in animations and movies. Behav. Res. Meth. 2010, 42, 179-187. [CrossRef] [PubMed]

80. Schrom-Feiertag, H.; Schinko, C.; Settgast, V.; Seer, S. Evaluation of guidance systems in public infrastructures using eye tracking in an immersive virtual environment. In Proceedings of the International Workshop on Eye Tracking for Spatial Research, Vienna, Austria, 22-27 September 2014.

81. Viaene, P.; Ooms, K.; Vansteenkiste, P.; Lenoir, M.; Maeyer, P.D. The use of eye tracking in search of indoor landmarks. In Proceedings of the International Workshop on Eye Tracking for Spatial Research, Vienna, Austria, 22-27 September 2014.

82. Afrooz, A.; White, D.; Neuman, M. Way-finding improves visual memory for built environments. In Proceedings of the International Workshop on Eye Tracking for Spatial Research, Vienna, Austria, 22-27 September 2014.

83. Ohm, C.; Müller, M.; Ludwig, B.; Bienk, S. Where is the landmark? Eye tracking studies in large-scale indoor environments. In Proceedings of the International Workshop on Eye Tracking for Spatial Research, Vienna, Austria, 22-27 September 2014.

84. Dong, W.; Liao, H. Eye tracking to explore the impacts of photorealistic $3 \mathrm{~d}$ representations in pedstrian navigation performance. ISPRS Int. Arch. Photogramm. Remote. Sens. Spat. Inf. Sci. 2016, 1, 641-645. [CrossRef]

85. Liao, H.; Dong, W.; Peng, C.; Liu, H. Exploring differences of visual attention in pedestrian navigation when using 2d maps and 3d geo-browsers. Cartogr. Geogr. Inf. Sci. 2016. [CrossRef]

86. Lei, T.C.; Wu, S.C.; Chao, C.W.; Lee, S.H. Evaluating differences in spatial visual attention in wayfinding strategy when using 2d and 3d electronic maps. Geojournal 2016, 81, 153-167. [CrossRef]

87. Viaene, P.; Vansteenkiste, P.; Lenoir, M.; Wulf, A.D.; Maeyer, P.D. Examining the validity of the total dwell time of eye fixations to identify landmarks in a building. J. Eye Mov. Res. 2016, 9, 1-11.

88. Franke, C.; Schweikart, J. Mental representation of landmarks on maps-Investigating cartographic visualization methods with eye tracking technology. Spat. Cognit. Comput. Int. J. 2016. [CrossRef]

89. Dong, W.; Zhang, S.; Liao, H.; Liu, Z.; Li, Z.; Yang, X. Assessing the effectiveness and efficiency of map colour for colour impairments using an eye-tracking approach. Cartogr. J. 2016. [CrossRef]

90. Krassanakis, V. Exploring the map reading process with eye movement analysis. In Proceedings of the International Workshop on Eye Tracking for Spatial Research, Scarborough, UK, 2-5 September 2013.

91. Krassanakis, V.; Filippakopoulou, V.; Nakos, B. Detection of moving point symbols on cartographic backgrounds. J. Eye Mov. Res. 2016, 9, 1-16.

92. Ooms, K.; Coltekin, A.; Maeyer, P.D.; Dupont, L.; Fabrikant, S.; Incoul, A.; Kuhn, M.; Slabbinck, H.; Vansteenkiste, P.; Haegen, L.V.D. Combining user logging with eye tracking for interactive and dynamic applications. Behav. Res. Meth. 2015, 47, 1-17. [CrossRef] [PubMed]

93. Poplin, A. How user-friendly are online interactive maps? Survey based on experiments with heterogeneous users. Cartogr. Geogr. Inf. Sci. 2015, 42, 358-376. [CrossRef] 
94. Kudelka, B.V.; Dobesova, Z. Eye-tracking testing of gis interfaces. In Proceedings of the 15th Internatianal Multidisciplinary Scienfific GeoConference, Sofia, Bulgaria, 16-19 June 2015.

95. Balzarini, R.; Murat, M. The effectiveness of panoramic maps design: A preliminary study based on mobile eye-tracking. Int. Arch. Photogramm. Remote. Sens. Spat. Inf. Sci. 2016, 2, 361-368. [CrossRef]

96. Çöltekin, A.; Lokka, I.; Zahner, M. On the usability and usefulness of 3d (geo)visualizations-A focus on virtual reality environments. Int. Arch.ives Photogramm. Remote Sens. Spat. Inf. Sci. 2016, 2, 387-392. [CrossRef]

97. Naspetti, S.; Pierdicca, R.; Mandolesi, S.; Paolanti, M.; Frontoni, E.; Zanoli, R. Automatic analysis of eye-tracking data for augmented reality applications: A prospective outlook. In Proceedings of the Third International Conference, AVR 2016, Lecce, Italy, 15-18 June 2016.

98. Wall, C.A.; Wang, Q.; Weng, M.; Kim, E.S. Mapping connections between biological-emotional preferences and affective recognition: An eye-tracking interface for passive assessment of emotional competency. In Proceedings of the International Conference on Affective Computing and Intelligent Interaction, Xi'an, China, 21-24 September 2015.

99. Cangöz, G. Effects of emotion and perspective on remembering events: An eye-tracking study. J. Eye Mov. Res. 2016, 9, 1-19.

(C) 2016 by the authors; licensee MDPI, Basel, Switzerland. This article is an open access article distributed under the terms and conditions of the Creative Commons Attribution (CC-BY) license (http://creativecommons.org/licenses/by/4.0/). 